\title{
Objetos de aprendizagem de autoria coletiva: uma concepção possível na $\mathrm{EaD}$ ?
}

\section{Learning Objects of collective authorship: a possible notion for Distance Education?}

\author{
MARISTELA VIGOLO FONTANA \\ Universidade Federal do Rio Grande do Sul e Universidade La Salle \\ ELAINE CONTE \\ Universidade La Salle
}

\section{ADILSON CRISTIANO HABOWKI}

Universidade La Salle

\begin{abstract}
Resumo: Esse estudo tem como objetivo empreender uma reflexão teórica sobre as práticas educativas que norteiam a construção de objetos de aprendizagem (OA) de autoria coletiva na educação a distância (EaD) diante das questões e desafios de reconstrução na formação humana. Trata-se de investigar, nas percepções de três coordenadoras de cursos a distância, se há como estabelecer relações associativas entre a construção de OA pelos participantes desses cursos e a formação da inteligência coletiva. O ensaio apresenta um panorama da constituição de OA em referenciais brasileiros e estrangeiros, por meio de um enfoque hermenêutico e de uma abordagem construtivo-colaborativa de experiências e concepções das professoras coordenadoras. Concluímos que a preocupação com a construção de OA de autoria coletiva contribui para a renovação dos diversos campos de saber, gerando benefícios formativos e contradições sobre os significados e os sentidos dos conhecimentos nas ações, inter-relações e atuações pedagógicas.
\end{abstract}

Palavras-chave: Objetos de Aprendizagem. Inteligência Coletiva. Tecnologias da Educação.

\begin{abstract}
This study aims to promote a theoretical discussion on the educational practices that guide the construction of Learning Objects (LO) of collective authorship in Distance Education (DE) to the issues and challenges of reconstruction in human formation. This is to investigate in the perceptions of three coordinators of distance courses, if there is to establish associative relations between the construction of LO by the participants of these courses and the formation of collective intelligence. The essay presents a panorama of the constitution of LO in Brazilian and foreign benchmarks, by means of a hermeneutical approach and a constructivecollaborative-approach of the experiences and conceptions of the coordinating professors. We conclude that the concern with the construction of the collective authoring LO contributes to the renewal of the various fields of knowledge, generating formative benefits and contradictions about the meanings and significances of expertise in the actions, interrelationships and Pedagogical performances.
\end{abstract}

Keywords: Learning objects. Collective intelligence. Education technologies. 


\section{Introdução}

Nesse universo plural de produção coletiva de conhecimentos em redes digitais, "a propensão à inteligência coletiva representa a possibilidade de aumento das capacidades cognitivas das pessoas e dos grupos, quer seja a memória, a percepção, as possibilidades de raciocínio, a aprendizagem ou a criação" (LEMOS; LÉVY, 2010, p. 14). O tema proposto enfoca uma dimensão do ato de educar colaborativo, em que os sujeitos são capazes de inventar, refletir, questionar e sugerir ações, em um ciberespaço democrático da expressão coletiva e da imaginação criadora. No processo de formação e de constituição histórica, ao mesmo tempo pessoal e coletiva, que prima pela capacidade de dialogar e pensar sobre as próprias experiências da cultura educativa, associações cognitivas e de deliberação dos sujeitos, surge essa pesquisa como possibilidade de enfrentamento das tensões e conflitos próprios $d$ as questões objetivas, subjetivas e sociais regidas pela ação pedagógica em EaD.

Há, na verdade, uma quantidade de objetos técnicos que povoam nosso inconsciente coletivo e atuam em nossa imaginação e linguagem. Daí a importância de uma revisão do agir educativo, no sentido de repensar e reconstruir novas abordagens formativas, para além das finalidades técnico-instrumentais e das simplificações cognitivas, incorporando as dimensões humanas, pedagógicas, cognitivas, afetivas, históricas, filosóficas e políticas. Afinal de contas, sem sujeitos não existiriam os $O A$, porque eles são fruto das percepções, construções, ressignificações e reelaborações humanas. No ensino, seja presencial, EaD ou online, há um enraizamento histórico da tradição cultural e uma prática social que orienta os processos de humanização. Com as mudanças nas formas de educar e trabalhar com o conhecimento, e com o avanço das tecnologias digitais, é necessário implementar ações cooperativas, de forma a avaliar criticamente a sociedade e a práxis profissional.

Sob essa ótica, cabe repensar experiências de incorporação dos conceitos virtuais em ações educativas, o que direciona nossas inquietações à seguinte questão: De que forma a construção de OA de autoria coletiva pode favorecer a formação da inteligência coletiva em contextos educativos? A pesquisa analisa as experiências de construção de $O A$, sob o ponto de vista de três professoras coordenadoras de cursos de EaD da Universidade Federal do Rio Grande do Sul (UFRGS), buscando compreender as relações associativas entre essa abordagem construtivocolaborativa para a formação da inteligência coletiva, extraindo elementos das apropriações e potencialidades de autoria coletiva. Os desdobramentos tomados por perspectivas diversas de teorias de aprendizagem alcançadas pela incorporação em ações educacionais aqui investigadas podem dar um entendimento mais profundo das relações de correspondência entre as características intrínsecas da EaD e alguns processos de reconstrução de OA (MOREIRA, 2011).

Para Tarouco et al. (2014, p. 2), um OA pode ser definido como "qualquer recurso, suplementar ao processo de aprendizagem, que pode ser reusado para apoiar a aprendizagem. O termo objeto educacional (learning object) geralmente aplica-se a materiais educacionais projetados e construídos em pequenos conjuntos", tendo em vista maximizar as situações de aprendizagem com o recurso. As análises das diferentes concepções e saberes pragmáticos dessa pesquisa foram realizadas por meio de um olhar hermenêutico e da aplicação de um questionário online com questões abertas. Por isso, refletir sobre o desenvolvimento e incorporação dos OA na ação docente, na troca de saberes e na construção de novas ações no ciberespaço também conferem importância à pesquisa. A escolha metodológica pela hermenêutica deve-se ao fato de que envolve um processo dialético e horizontal de compreensão e interpretação humana, que brota do não saber e que busca um diálogo vivo com a realidade, de abertura para o aprender com o outro (GADAMER, 1999). "Podemos ultrapassar reflexivamente nossas posições de partida hermenêuticas a cada vez diferentes e chegar a concepções partilhadas sobre uma coisa disputada" (HABERMAS, 2002, p. 57). Assim se evidencia na atitude hermenêutica o caráter cooperativo das disputas pelo melhor argumento na (re)construção de novos entendimentos sobre o mundo possibilita a participação do sujeito na construção do objeto e vice-versa (HABOWSKI; JACOBI; CONTE, 2018). 
A seguir, tecemos reflexões sobre os discursos e compreensões vigentes sobre OA, bem como identificamos o desenho do estudo e os referenciais para o ensino superior, tendo em vista a elaboração de OA que respondam à reconstrução desses materiais educacionais digitais. $\mathrm{Na}$ sequência, nos debruçamos sobre as apreciações das concepções das professoras e as ressignificações com base nas experiências realizadas pelas coordenadoras dos cursos de EaD e as considerações finais.

\section{Apreciações e desenho do estudo}

Com a efervescência da EaD no cenário nacional, a partir do ano 2000, houve uma rápida expansão dessa modalidade de ensino, através de políticas públicas voltadas para a formação de professores em exercício nas redes públicas de Educação Básica. Vale ressaltar, portanto, que a intenção foi suprir as demandas da sociedade para formação de professores em exercício nas redes públicas, de educadores sem uma formação condizente com sua área de atuação. Para estimular a formação inicial e continuada de professores, foram ofertados diversos cursos de graduação e de especialização na UFRGS, como por exemplo, os cursos de Artes Visuais, Música e a especialização em Mídias na Educação, que serão evidenciados sob a perspectiva das professoras coordenadoras desses cursos voltados para a integração pedagógica das diferentes mídias e dos conteúdos educacionais de linguagens tecnológicas. Os dois cursos de licenciatura em EaD pesquisados, Artes Visuais e Música, de edição única, tiveram início entre 2007 e 2008 e a sua conclusão em 2012. Os estudantes e professores desses cursos tiveram que desenvolver um OA de autoria coletiva, como um dos pré-requisitos para a sua diplomação. O intuito dos cursos foi não só promover a inclusão digital, mas a fluência digital, buscando qualificar a Educação Básica por intermédio da inserção e do uso das tecnologias digitais e pela titulação e qualificação de seus professores. A partir destas experiências de inovação pouco habituais em contextos formativos, buscou-se, através da visão de três professoras coordenadoras, rastrear as facetas educativas à construção de OA de autoria coletiva.

O problema de investigação foi sistematizado mediante a produção de dados por meio de um questionário enviado online pelo Google Forms, a fim de compreender as complexidades dessa incorporação prática e construtivo-colaborativa de OA de autoria coletiva, bem como das contradições encontradas nesse processo e as repercussões formativas e sociais para o processo de ensino e de aprendizagem. Com isso, tentamos evidenciar, por meio de três questões abertas às docentes, seus discursos e compreensões acerca dessa temática, para assim, mergulhar nas possibilidades de ressignificação das experiências pedagógicas, voltadas para a autonomia, autoria, colaboração e construção de saberes na rede e em rede (LÉVY, 1998).

O conceito de OA é complexo e dinâmico e, por isso, não há um consenso em relação a sua definição, nem mesmo para a sua nomenclatura, sendo também chamado de objetos educacionais, de objetos virtuais de aprendizagem, de materiais educacionais digitais, etc. Objetos de Aprendizagem de autoria permitem a produção de conteúdos pedagógicos digitais, associando novas abordagens pedagógicas ao potencial da informática, por intermédio de um processo coletivo e colaborativo. Flôres (2011, p. 56) afirma que a tecnologia educacional vem facilitar o trabalho do professor, sem que ele "seja um programador, usando estruturas e procedimentos já programados, reunindo-os, agregando conteúdo e forma de tratamento de dados que dependem de sua estratégia pedagógica".

Segundo Ayub, Carvalho e Teixeira (2006, p. 29), para atingir a eficiência de um OA, é necessária uma equipe multidisciplinar, "o trabalho conjunto dos professores de educação, designer pedagógico, usabilidade (do ponto de vista da ergonomia cognitiva), dos padrões estéticos e atrativos, do ponto de vista da comunicação propostos pelos designers", bem como o "contexto econômico, cultural, social e a faixa etária dos usuários são elementos relevantes na adequação da linguagem adotada". Nesse caso, o uso pelo professor desse tipo de ferramenta vai além apenas do processo de apropriação da tecnologia, visto que impõem replanejar 
situações a partir das novas exigências do desenvolvimento funcional e motivacional. A possibilidade de desenvolver o seu próprio conteúdo digital, a partir de ferramentas de autoria, favorece uma atuação mais ativa e efetiva do professor que se sente mais integrado ao processo como um todo, propiciando material em consonância com o contexto cultural do seu públicoalvo. O estudante, consequentemente, também se sente motivado e envolvido na construção do OA porque tem suas necessidades, capacidades e potencialidades reconhecidas, além de atribuir mais autonomia para o professor e os estudantes, que em coautoria usam o software e reconfiguram o trabalho coletivo.

\title{
3 OA na percepção das coordenadoras dos cursos - resultados
}

Tendo em vista que os processos de ensino a distância são dinâmicos e moventes, buscamos compreender por meio da pergunta: Qual é o seu entendimento de objeto de aprendizagem de autoria coletiva?, a relevância e as tensões constitutivas dessa experiência de aprendizagem para a formação coletiva. Ao perguntar sobre o que seria um OA de autoria coletiva, a professora 3 diz: "um Objeto de Aprendizagem cuja autoria é realizada por mais de uma pessoa, de forma colaborativa". Quanto ao entendimento da professora 1, essa experiência possibilita duas abordagens em relação ao significado de OA: a primeira, relacionada ao desenvolvimento de um $\mathrm{OA}$, que envolve distintas áreas do conhecimento de forma interdisciplinar e transdisciplinar; e a segunda, relacionada à autoria coletiva e colaborativa. Além disso, considera que em ambas as abordagens a aprendizagem é concebida pela construção de relações desafiadoras e inquietantes com o outro, sendo as diferenças um propulsor para novas aprendizagens.

\begin{abstract}
O primeiro está relacionado à construção interdisciplinar e transdisciplinar de um objeto de aprendizagem envolvendo distintas linguagens e áreas de conhecimento, enfatizando tanto a operacionalidade como a diversidade do uso pedagógico do objeto. O segundo está relacionado à autoria coletiva colaborativa quando a operacionalidade técnica e/ou tecnológica já está definida e a ênfase recai somente na construção didático-pedagógica colocando em sintonia a diversidade interna a uma única área de conhecimento, a partir das diferenças constitutivas. É importante mencionar que tanto na primeira como na segunda o principal aprendizado ocorre na forma de construir relações e compreender e aceitar as diferenças, verificando que são as diferenças que possibilitam a própria construção (PROFESSORA 1).
\end{abstract}

Sabemos que todas as pessoas têm um estilo próprio de aprender e que precisam ser orientadas, conforme suas necessidades, contextos e interesses. Na verdade, todos nós somos para os outros uma oportunidade de aprendizado e nos constituímos de um imaginário social experimentado nas relações humanas, cujo reconhecimento encoraja novas práticas profissionais, sociais, culturais e conhecimentos da experiência cotidiana de sentido comunitário. $\mathrm{Na}$ perspectiva da professora 1, o trabalho, quando elaborado de forma colaborativa, em busca de um objetivo comum, oportuniza uma visão mais ampla e reflexiva de conhecimento, em que o ponto de vista e a opinião do outro são respeitados, motivando revisões e atualizações, melhorando inclusive a qualidade da convivência social, cujas diferenças é que desafiam e impulsionam a concretização de aprendizagens à imaginação criadora. Bransford, Brown e Cocking (2007, p. 288) afirmam que "a cooperação cria um ambiente no qual os participantes podem contribuir de acordo com o que são capazes e aprender a partir das contribuições dos que são mais competentes", visto que a troca de ideias com os outros é uma fonte de estímulo.

No contexto de interação dialógica, a empatia necessita ser constantemente aprimorada, sendo uma habilidade social fundamental que abre espaço para as dimensões estéticoexpressivas e emocionais dos sujeitos. Na visão de Lévy (1998, p. 37), seria a hospitalidade e a 
solidariedade que acolheria o indivíduo a um coletivo, tendo em vista que "pela hospitalidade, aquele que é separado, diferente, estranho é acolhido, integrado, incluído em comunidade. A hospitalidade consiste em atar o indivíduo a um coletivo". A professora 1 nos diz que aceitar as diferenças contribui com a realização de um projeto coletivo. Essa interação dialética "estabelece um forte vínculo intelectual com seus colegas e conserva o interesse e o desafio necessários para manter o vigor na sala de aula" (BRANFORD; BROWN; COCKING, 2007, p. 247). Convergindo com isso, Lévy (1998, p. 31) reforça que, na interação "com diversas comunidades, os indivíduos que animam o Espaço do saber, longe de serem os membros intercambiáveis de castas imutáveis, são ao mesmo tempo singulares, múltiplos, nômades e em vias de metamorfose (ou de aprendizado permanente)", em um ciclo constante de escuta, expressão, tomada de decisão e reavaliação.

A outra questão colocada pela professora 1 é a necessidade do envolvimento de distintas linguagens e áreas do conhecimento, no que se refere à operacionalidade e à diversidade no uso pedagógico para a construção de OA de autoria coletiva. Depreendemos que para a construção de um OA é necessário conhecer o tema que será abordado, definir qual abordagem pedagógica irá nortear as formas de uso e ter coerência quanto aos princípios de autoria de um projeto social aprendente dos códigos dessa linguagem. Sob essa perspectiva, é importante fornecer atividades ao estudante, para que ele se envolva em experiências concretas, por meio de "observações e reflexões sobre seu contato com o mundo, elaborando conceitos abstratos e generalizações que permitem um novo contato com a realidade, com o objetivo de testar os resultados e suas implicações em novas situações por meio da experimentação ativa" (FLÔRES, 2011, p. 112).

Para o desenvolvimento dessa proposição de construção de OA, a interdisciplinaridade seria uma forma de desfragmentar e dar sentido ao conhecimento, sendo o elo que une as diferentes esferas do saber para a formação de uma ideia mais ampla sobre as dinâmicas do mundo que impactam as práticas pedagógicas. Nessa perspectiva, o professor não fica preso a um único conteúdo, mas busca uma possibilidade científica, fundada no desejo de inovar, criar, aprender, pesquisar, colaborar na magia do encontro. O professor precisa orientar o estudante rumo ao aprender por meio de vínculos de aprendizagem, instigando a inteligência cognitiva e emocional para a resolução de problemas numa ação repleta de sentido. Assim, "ocorre uma prática inter e transdisciplinar, quando a produção do conhecimento é vista de forma aberta, espiral, sem limites, hierarquias ou superioridades" (FERREIRA, 2007, p. 155).

A transdisciplinaridade seria uma opção à resolução de problemas contemporâneos de alta complexidade. Segundo Ferreira (2007, p. 21), num modelo transdisciplinar, "todos os saberes possuem importância e a relação que um saber mantém com o outro é de natureza dialógica. Não existe uma disciplina mais significativa do que a outra e não existe um conhecimento mais significativo do que o outro". Existem, portanto, "significações contextualizadas. No modelo de currículo transdisciplinar, a produção do conhecimento é resultado de um processo que não tem final determinado: é aberta, incessante" (FERREIRA, 2007, p. 21). Ao propor metodologias de natureza dialógica, com ações de pesquisa e práticas colaborativas, temos que avaliar o envolvimento com o processo e suas potencialidades. Na posição da professora 2, a abordagem tem um altíssimo potencial para a aprendizagem, desde que coordenado por um professor ou um pesquisador.

Excelente método de trabalho, com altíssimo potencial positivo para a aprendizagem de todos os envolvidos, desde que devidamente suportado por orientações pertinentes ao caso, sob a responsabilidade de um professor ou pesquisador, que assuma a tarefa de coordenar a equipe, de modo flexível e aberto. Tais orientações devem incluir clareza quanto: ao tema em foco, incluindo seu público-alvo e a profundidade, com que o assunto deverá ser abordado; e ao estilo da apresentação do produto final e a tecnologia a ser utilizada. Também deverá prever os perfis dos componentes da equipe de trabalho e suas capacidades individuais, antecipando possibilidades de atendimento para eventuais lacunas, por exemplo. 
Ao pensar nesta abordagem construtivo-colaborativa, sugere-se um pensar de bases epistemológicas que supere a ingenuidade da simplificação dos conhecimentos, o que significa "ser produzido pelo próprio aprendiz em comunhão com o professor formador" (FREIRE, 2011, p. 39). Nas palavras de Freire (2011, p. 39), "a prática docente crítica, implicante do pensar certo, envolve o movimento dinâmico, dialético, entre o fazer e o pensar sobre o fazer". A resposta da professora 2 nos apresenta estratégias para nortear as ações dos participantes de forma mais dialógica, aberta e flexível, no que se refere à construção de um OA de autoria, objetivando uma formação cultural coordenada comunicativamente, num ambiente cada vez mais multicultural e plural que os espaços educativos comportam. Sendo assim, os professores precisam estar "preparados para ensinar um grupo cada vez mais diverso, com padrões cada vez mais elevados de desempenho acadêmico" (BRANSFORD; BROWN; COCKING, 2007, p. 257). Os relatos das experiências das coordenadoras nos cursos de EaD mostram também a importância da construção e uso das tecnologias digitais e de outros recursos didáticos, de modo a apresentar um produto final que seja relevante quanto aos requisitos técnicos e pedagógicos e que envolva interação e interatividade.

Prata, Nascimento e Pietrocola (2007, p. 108) ressaltam que a produção dos OA "interativos e com qualidade pedagógica para as diversas áreas de conhecimento da Educação Básica tem sido um grande desafio para o MEC e para todos que atuam nessa área", pois não se trata somente do deslocamento de textos didáticos para um formato multimídia, mas da produção de ações interativas, integrando novas estratégias metodológicas dos professores. Dessa forma, a ideia de construção de OA é disponibilizar um material educacional digital aberto, que possa ser constantemente aperfeiçoado. Nascimento (2007 p. 137) esclarece que um OA mal elaborado pode falhar quanto aos seus propósitos, pois os estudantes já usam com frequência "softwares, videogame e outras mídias, e têm expectativas altas sobre qualidade, acesso e interatividade. Se uma simulação, ou um jogo educativo é mal planejado ou mal implementado pode falhar completamente em atingir os objetivos de aprendizagem".

Para a (re)elaboração do material, temos que pensar, também, na confiabilidade e na qualidade do conteúdo proposto, ou seja, nos referenciais e autoria do material produzido, para ter segurança da qualidade e confiabilidade do aparato a ser utilizado. Outra questão que deve ser destacada, ao pensar sobre a prática, é quanto à autoria nos processos educativos, buscando processos mais ativos, que preparem os estudantes para uma "adaptação flexível aos novos problemas e cenários", aproximando-os do seu contexto sociocultural, contribuindo com sua a autoestima ao construir o seu próprio material didático e tornando-os pesquisadores (BRANSFORD; BROWN; COCKING, 2007, p. 109). Em vez de colocar o foco nos artefatos que dão vazão ao conhecimento, Costa (2014, p. 34) defende a estimulação de modos inéditos de práticas pedagógicas e percebe que "a criação de material didático por professores e alunos é uma excelente forma de fazer com que a realidade de cada escola, cidade, estado, seja reapresentada e trabalhada em sala de aula", pois o estudante se reconhece como autor dos materiais produzidos, reforçando a sua autoestima e se sentindo atraído pelo ato de pesquisar e aprender. Além disso, o professor não é um recebedor dos "materiais selecionados, editados e empacotados para consumo e torna-se um agente ativo no processo de pesquisa, seleção, edição e elaboração de seu próprio material que, ao ser disponibilizado de forma aberta na rede, passa a receber contribuições dos colegas" (COSTA, 2014, p. 34).

A construção de OA de autoria coletiva contribui com a autoestima do estudante e com a sua motivação, visto que os "aprendizes de todas as faixas etárias sentem-se mais motivados quando reconhecem a utilidade do que estão aprendendo" (BRANSFORD; BROWN; COCKING, 2007, p. 88). Essa ação conjunta permite interações dialéticas, recriações coletivas, imaginação e colaboração, movimentando o potencial do ciberespaço e a formação da inteligência coletiva. Um conjunto de novos hábitos nesse cenário suscita maior expressão da diversidade e de produção de conteúdos culturais. Temos que aproveitar a potência que as tecnologias nos oferecem para produzir conteúdo próprio, compartilhando informação, movimentando espaços de conhecimentos, enriquecendo a cultura local e global, tornando os sujeitos capazes de atualizar 
conhecimentos e se reinventar (LEMOS; LÉVY, 2010). Essa relação intersubjetiva é um ato performático ligado às estruturas discursivas em processo de (re)criação, "florescendo aos ritmos das invenções, das descobertas", rumo a uma educação para o século XXI (LÉVY, 1998, p. 181).

\section{OA em relação com a formação coletiva}

Neste tópico, busca-se fazer relações entre essa abordagem construtivo-colaborativa, mediada pelo uso das tecnologias digitais, e a formação da inteligência coletiva. Lévy (1998, p. 29) diz que "a coordenação das inteligências em tempo real provoca a intervenção de agenciamentos de comunicação que, além de certo limiar quantitativo, só podem basear-se nas tecnologias digitais de informação". Afirma ainda que é "por isso que a invenção de novos procedimentos de pensamento e negociação que possam fazer emergir verdadeiras inteligências coletivas se faz urgente" (LÉVY, 1998, p. 15). Sob essa perspectiva, precisamos "desenvolver até o máximo suas potências criativas, seja criando negócios e teorias ou então inventando ferramentas e produtos, de acordo com as habilidades de cada um" (LÉVY, 2003, p. 24).

A fim de constatar essa metamorfose, a segunda pergunta examina o que as professoras coordenadoras dos cursos de licenciatura e especialização em EaD tem produzido nos últimos tempos, utilizando a seguinte colocação: esta abordagem mais dialógica, de projeto de pesquisa, de prática colaborativa e de criação coletiva, contribui para a formação da inteligência coletiva, indo além da mera transmissão de conteúdos? A professora 2 considera essa proposição um excelente método ao desenvolvimento de práticas interativas, porém ela adverte que, em dada circunstância, alguns estudantes podem se apropriar mais de um determinado conhecimento que outros, em função do domínio das tecnologias, por exemplo, podendo ficar mais restrito aos estudantes com maior fluência digital, criando uma lacuna de conhecimento (knowledge gap) para os estudantes que não foram incluídos digitalmente. Segundo Lévy (1998, p. 181), é impossível que alguém possa dominar todos os conhecimentos ou todas as competências, isso porque, o saber da comunidade pensante não é mais um saber comum é "um saber coletivo por essência, impossível de reunir em uma só carne". Para que as lacunas de conhecimento sejam superadas, é necessário privilegiar os movimentos de expressão do cotidiano e estar atento à divisão de tarefas para que ela ocorra de forma mais equitativa, para que todos os talentos possam ser contemplados nas manifestações contemporâneas. Para Lévy (1998, p. 71), "o ato seguinte da inteligência coletiva, o da organização, consiste em distribuir funções e órgãos na cidade, dividir tarefas, reagrupar forças e competências". A visão da professora 2, quanto à abordagem construtivo-colaborativa, sugere uma prática que demanda como também estimula o desenvolvimento de modos inovadores de ser e de estar no mundo, distanciando-se dos objetivos de mera transmissão de conteúdos, porém:

[...] isso não é um processo automático. A propósito, dependendo de como for conduzido, pode até aumentar o Knowledge Gap, o que muito se tem constatado! É preciso considerar que a tecnologia não é a panaceia para todos os problemas de ensino-aprendizagem. Assim, as dificuldades e conflitos humanos, bem como suas qualidades, continuam as mesmas, ao se produzir um OA de autoria colaborativa, daquelas encontradas em qualquer trabalho de equipe. É fácil que o processo seja desequilibrado em termos de esforços empenhados, por exemplo. Também é fácil acontecer maior peso numa particularidade do que em outra, mesmo que potencialmente todos os talentos pudessem ser contemplados (PROFESSORA 2). 
O que está ocorrendo, de acordo com a abordagem construtivo-colaborativa da professora 1 é que a inteligência se dá na experiência da linguagem.

\begin{abstract}
A construção dialógica, colaborativa e/ou coletiva envolvendo investigação, práticas e criação possibilita o desenvolvimento da inteligência na experiência da linguagem, que é justamente o lugar da diferença e da interação com o outro. Segundo Maturana e Varela somos seres da linguagem e o conhecimento dá-se na linguagem (PROFESSORA 1).
\end{abstract}

Nesse cenário, o conhecimento acontece a partir de processos sociais em uma dinâmica constante de interação e troca entre o mundo e os sujeitos, que, através de um complexo sistema de cognição, as interações e as percepções, modifica o meio e muda as subjetividades, transformando-se mutuamente (MATURANA; VARELA, 2002). Para os autores, a percepção seria constituída por intermédio da ação dos sujeitos no mundo e pela sua reflexão que seria o pensar sobre o pensar e reconhecer como se conhece, sobretudo, porque "todo fazer é um conhecer e todo conhecer é um fazer" (MATURANA; VARELA, 2002, p. 32). Sob essa perspectiva, a professora 1 avalia que a inteligência e o conhecimento se dão através de processos sociais dialógicos, de prática colaborativa que requer investigação e um saber fazer criativo - fator envolvido nessas interações.

Mergulhar nessa lógica de OA gera paradoxos formativos nas práticas de EaD, mas, ao mesmo tempo, converte-se numa aventura fascinante com indagações, desdobramentos e perspectivas inovadoras de ensino. Essa proposta, na opinião da professora 3, "tem grande potencial para contribuir na socialização dos saberes e ampliar a ZDP - Zona de Desenvolvimento Proximal, conforme definido por Vygotsky". Para Vygotsky (1998), a ZDP é alimentada por meio das discussões em processos socioculturais onde os níveis de conhecimento preexistente são expandidos e estimulados com o outro, tendo em vista a resolução de problemas de forma autônoma. O desenvolvimento proximal seria a zona em que a aprendizagem vai ocorrer, quando intermediada por alguém mais experiente, como um professor ou um colega, por exemplo, que seria um interlocutor em potencial para a resolução do problema colocado em evidência. Isso, para Vygotsky (1998), relaciona-se à oportunidade de entender e de ser entendido, de comunicar-se e educar-se com os demais, tendo na inquietação e interpelação com o outro um fator que impulsiona o desenvolvimento da mentalidade coletiva. A ZDP é uma caminhada indispensável rumo ao conhecimento evolutivo de um processo potencializado nos jogos comunicativos enraizados nas relações entre o individual e o social. A aprendizagem se dá no constante processo de interação ativa, favorecendo a curiosidade, o questionamento consigo, com o outro, com os objetos, enfim, com o mundo da reflexão e da apropriação do conhecimento. Em virtude do movimento projetivo de onde é protagonizado o OA de autoria coletiva, as professoras coordenadoras depositam confiança nessa metodologia construtivo-colaborativa. Porém, alguns aspectos contraditórios foram observados, especialmente na terceira e, portanto, última pergunta comentada, a saber: quais os aspectos relevantes ou as contradições encontradas, quanto a essa abordagem metodológica, para o processo de construção de um OA de autoria coletiva?

Segundo a professora 2, mesmo com as imensas potencialidades das redes digitais, ainda vigora o analfabetismo digital em alguns usuários. De fato, a proposição da construção de $O A$ pode ter representado um grande desafio para os estudantes e professores dos cursos, já que muitos tiveram que ser incluídos digitalmente por serem imigrantes em formação. Segundo Nunes, Rangel, Schramm (2012, p. 297), o desafio quanto à inclusão digital foi totalmente superado, conforme investigado no final do curso, " $0 \%$ dos alunos assinalou falta de familiaridade com recursos digitais e internet, quando foi perguntado sobre fatores de entrave aos estudos". Essa afirmação se refere, principalmente, aos jovens diplomados, já que houve um índice de evasão no decorrer dos cursos.

As interferências, admite a professora 2, podem acompanhar alguns estudantes que se encontram em níveis mais avançados que outros, tornando assim, o processo desequilibrado em termos de esforços empenhados, já que uma das competências necessárias para 0 
desenvolvimento de um OA se refere ao domínio das tecnologias. Para a professora 2, "um $O A$ de boa qualidade nunca é feito por uma única pessoa". Sendo assim, foi necessário explorar os múltiplos talentos e a potência de invenção coletiva, em várias áreas do conhecimento, para a conclusão do projeto. Por isso, agora, o saber da comunidade pensante não é mais singular, mas um saber que brota da prática social e que oportuniza uma intercomunicação planetária pelo ciberespaço, em uma vasta cooperação cognitiva distribuída por toda parte. Na opinião da professora 2:

\begin{abstract}
As contradições estão presentes desde o analfabetismo digital, vencido por alguns e por outros, não. Ainda é preciso enfrentar preconceitos contra uma educação mediada por TIC e, por mais absurdo que isso possa parecer, preconceitos encontrados inclusive entre intelectuais e professores com carreiras consolidadas. Muitas vezes, o medo e o constrangimento pelo desconhecimento do mundo virtual mediado por tais recursos, estão disfarçados de menosprezo e revestidos de explicações supostamente qualificadas e cheias de autoridade. É grande o peso de decisões tomadas por aqueles que detêm o poder sobre processos educacionais e políticas públicas; e muitas dessas pessoas são incapazes de assimilar a rapidez com que a sociedade mudou e está mudando. Tal velocidade de investida num mundo imaterial, como ao que as TIC nos levam, assusta; e a defesa toma a forma de travas, numa tentativa de deixar tudo "de um jeito que eu possa compreender". Quando tais limitações particulares influenciam decisões públicas, as contradições se tornam perigosas. A EaD desmascara antigos vícios e falhas da educação presencial tradicional, apenas isso. Tanto, que em decisão recente, o CNE deixou de considerá-la uma modalidade de ensino, porque, de fato, não o é; trata-se de mais um método, com suas próprias ferramentas; obviamente, ferramentas eficazes no desmascarar de falhas, que, de tão antigas, já tinham conseguido bons disfarces...
\end{abstract}

É possível ir ainda mais longe na experiência do trabalho, quando a professora aponta uma barreira ainda maior no que se refere ao preconceito entre alguns intelectuais e professores quanto ao uso das tecnologias digitais para o ensino, podendo até influenciar negativamente em políticas públicas para o setor, aniquilando ou abandonando possibilidades de inovação na área. Segundo a professora 1, uma abordagem plural que envolva a dialogicidade, a colaboração e o coletivo, parte de princípios éticos em que o conhecimento é partilhado, oportunizando uma comunicação social mais interativa e planetária, que se apropria das diferenças constitutivas dos sujeitos, oportunizando um gesto coletivo. Mesmo que a obra (OA) não exista antes do trabalho iniciar, a falta de disposição para aprender com as outras pessoas podem representar entraves culturais, sociais, econômicos, educacionais e políticos, visto que nem sempre é espontânea. Dessa forma, para que se tornem experiências significativas de aprendizagem precisamos de condições éticas, o que implica valorizar o outro e desafiá-lo para que possa superar as deficiências e desigualdades, desenvolvendo valores, atitudes e o comportamento responsável nos espaços formativos. Para a professora 1, é importante nos apropriarmos das diferenças constitutivas dos sujeitos, já que somos para o outro uma oportunidade de renovação de saberes e de crescimento intelectual, afetivo, perceptivo e criativo, pois o contato com o outro dá vitalidade ao processo de aprender, rumo ao sucesso da obra coletiva. Para a professora 3, "a colaboração demanda acesso compartilhado a um espaço de trabalho comum e coordenação de esforços para que os esforços se complementem e alinhem de forma sinergética. Para isto comunicação entre os participantes é também relevante".

Vale a pena citar aqui que para a construção do projeto construtivo-colaborativo é necessário - entrelaçamento de diversas áreas do conhecimento, envolvendo os diversos atores, oportunizando a tomada de decisão que contribui com a cognição. Ao propor a construção de um OA de autoria coletiva, o professor necessita orientar os estudantes com relação aos objetivos e metas a serem alcançados, para que eles não se sintam desamparados e desmotivados a continuar. O professor precisa promover a troca de saberes entre os diversos atores de forma horizontal, já que a "transferência de autoridade, com a adoção da participação cooperativa, 
resulta diretamente de uma motivação cognitiva intensa, ao mesmo tempo em que contribui com ela" (BRANSFORD; BROWN; COCKING, 2007, p. 288). Afinal de contas, "há que se compreender e incorporar as novas linguagens digitais à reeducação dos conhecimentos, criando vínculos autônomos e cooperativos para fazer valer a autoridade da autocrítica e das inter-relações humanas" (CONTE; HABOWSKI, 2018, p. 406). Em contextos mais estimulantes e desafiadores, os estudantes tendem a persistir "porque o sucesso e a compreensão são motivadores por si mesmos" (BRANSFORD; BROWN; COCKING, 2007, p. 296).

Sob esta ótica, não se pode ignorar as mudanças cognitivas que as tecnologias digitais têm provocado, com múltiplas possibilidades de aprendizagem, como a criação de laboratórios de pesquisa online (CONTE; HABOWSKI; RIOS, 2019). Esta participação coletiva e colaborativa, através de comunidades virtuais de aprendizagem, tanto locais como globais, oportuniza a criação e a produção de novos artefatos culturais, em tempos síncronos e assíncronos. A interconexão das redes e o ciberespaço tem propiciado para pesquisadores, cientistas e outros profissionais a criação de "laboratórios colaborativos ("colaboratórios") eletrônicos, por meio dos quais definem e realizam seu trabalho. Esta tendência fornece tanto uma justificativa quanto um meio para o estabelecimento de comunidades virtuais com finalidades de aprendizagem" (BRANSFORD; BROWN; COCKING, 2007, p. 270).

As comunidades virtuais seriam uma maneira distinta que tem o potencial de encurtar as distâncias, evitando o isolamento e evasão, pretendendo conduzir o estudante a uma eterna busca. "Uma tal busca não se faz no isolamento, mas na comunicação entre os homens" (FREIRE, 1983, p. 82). A comunicação aberta contribui para que todos ensinem e aprendam, oportunizando uma atuação e correlação pedagógica com o outro no mundo, através do ciberespaço, que "tornar-se-ia o espaço móvel das interações entre conhecimentos e conhecedores de coletivos inteligentes desterritorializados", tornando metamorfoseante e nômade do saber (LÉVY, 1998, p. 29). Essas comunidades aprendentes rompem com a suposta legitimidade de que uns sabem e outros, por não saber, apenas consomem e reproduzem. Segundo Lévy (1998, p. 31), num "coletivo inteligente, a comunidade assume como objetivo a negociação permanente da ordem estabelecida, de sua linguagem, do papel de cada um, o discernimento e a definição de objetivos, a reinterpretação de sua memória". Esta negociação permanente desmascara verdades inquestionadas e falsos autoritarismos espetacularizados, que produzem discursos vazios de conteúdo. A professora 2 diz que:

As autorias colaborativas, por exemplo, desmascaram o autoritarismo, as pompas das cátedras, rompem com a suposta legitimidade de que uns sabem e mandam, enquanto outros não podem saber e obedecem. Um OA de boa qualidade nunca é feito por uma única pessoa; são necessários especialistas de várias áreas, pois ele é multidisciplinar. E tais especialistas precisam se respeitar, antes de tudo, e terem um código comum, em seguida. Mas isso implica destituirse de poder único em si. E ter medo de perder supremacia é um sentimento humano, não um problema tecnológico. Então, as abordagens metodológicas de um mundo midiatizado devem ocupar-se com a pessoa, primeiro. E essa também é uma contradição interessante!

Podemos constatar, conforme o relato da professora 2, a necessidade de pensadores de várias áreas para a construção de um $\mathrm{OA}$ e o entrelaçamento de conhecimentos, a fim de se ambicionar resultados positivos e de não cometer os mesmos erros do passado, ao incorporar de forma compensatória os materiais didáticos ou por modismos de uma falsa modernização da educação. Quanto ao "poder único em si", citado pela professora 2, esse pensamento vai ao encontro de Sancho e Hernándes (2006, p. 19), quando afirmam que a tecnologia "parece se encontrar no fato de que a tipologia de ensino dominante na escola é centrada no professor" e nas metodologias que separam a aprendizagem da construção do conhecimento.

A contradição ocorre por conta do choque entre metodologias que separam a aprendizagem da construção do conhecimento e do ensino, fixando os sujeitos em lugares hierarquizados, com impossibilidade de movimentação. A passagem 
de uma abordagem a outra é feita de ambiguidades e gera contradições ao não se explicitar o lugar de onde se está falando. A explicitação possibilitaria a passagem da relação de contraditórios a contrários, apropriando as diferenças como parte constitutiva, levando a hierarquias móveis e, por fim, ao desenvolvimento coletivo (PROFESSORA 1).

Essa reflexão pode explicar, em certa medida, a renovada necessidade que o professor tem de repensar o sentido da educação e sentir-se preparado e disposto a mudar e a renovar suas práticas, através da investigação coletiva. Porém, Bransford, Brown e Cocking (2007, p. 259) salientam a necessidade de rever e desmistificar a pesquisa como algo só para especialistas e desnecessária na escola, pois, na educação escolar, os estudantes e professores "precisam aprender sobre as descobertas advindas da pesquisa". Tudo indica que produzir conteúdos autorais em rede, proposto para os estudantes e professores "pode ajudar estudantes e professores a desenvolver as competências necessárias para o século XXI" (BRANSFORD; BROWN; COCKING, 2007, p. 263). A possibilidade de criação de OA contribui e dialoga com o princípio de pesquisa no ciberespaço. Na verdade, "fora da coletividade, desprovido de tecnologias intelectuais, "eu" não pensaria. O pretenso sujeito inteligente nada mais é que um dos micro atores de uma ecologia cognitiva que engloba e restringe" (LÉVY, 1993, p. 137). Assim, podemos afirmar que abordagens dialógicas de percepção criativa propiciam novas formas de aquisição de conhecimento. Lévy $(1998$, p. 71$)$ considera ainda a necessidade de ouvir o outro, em uma escuta contínua e aberta aos membros de outras sociedades, então, os "indivíduos e grupos que animam a cidade inteligente podem exprimir os problemas que lhes parecem mais importantes para a vida coletiva, tomar posição sobre estes problemas e formular argumentos em apoio a estas posições", aprendendo de modo interdependente.

Contudo, para o aperfeiçoamento do projeto e para a resolução de problemas, podemos usar outras estratégias, como fazem os brasileiros do portal Transparência Hacker ${ }^{1}$, produzindo e disponibilizando conteúdos e produtos no ciberespaço, para que sejam testados e melhorados por todos, a partir de um debate coletivo e de compartilhamento de saberes. Esse sujeito aberto, que pertence a uma comunidade pensante, pesquisa, escreve, conecta, consulta, cria, imagina, explora, porque "seu saber coletivo se materializa em uma imensa imagem eletrônica pluridimensional, quase viva em perpétua metamorfose" (LÉVY, 1998, p. 181). Esse metamorfosear e produzir metáforas fortes em redes virtuais leva os sujeitos à construção de uma inteligência coletiva que se dá pela intercomunicação no ciberespaço, renovando os saberes sociais e potencializando uma vontade coletiva de (re)aprender e (re)conhecer com o outro.

\section{Considerações finais}

Ao significarmos as respostas da amostra por seleção sobre o entendimento da experiência construtivo-colaborativa de OA nos três cursos de EaD, percebemos o quanto a cultura digital transforma as relações humanas e repercute nas práticas pedagógicas e sociais. Tais concepções provocam à abertura a novos modos de ver, à imaginação criadora e à capacidade de reconstruir e aprender, pois foram implementadas em espaços de reflexão e ações coletivas, associadas ao ensino e à pesquisa, com abordagens complexas e promissoras que envolvem uma prática plural de realização de projetos coautorais. Essa experiência aconteceu em um espaço formativo muito específico, com os estudantes e professores dos cursos de EaD da instituição, sendo um público

\footnotetext{
1 Para saber mais sobre as ações da Transparência Hacker Brasil, consultar os seguintes (hyper)links: http://www.canalibase.org.br/somos-a-transparencia-hacker/ ; http://br.okfn.org/tag/transparenciahacker/; http://www.tecmundo.com.br/governo/19650-transparencia-hacker-site-permite-interagir-comgovernantes-e-eles-sao-obrigados-a-responder-voce-.htm http://politica.estadao.com.br/blogs/publicos/transparencia-hacker-vence-concurso-da-fundacaorockefeller/. Acesso em: 26 set. 2018.
} 
mais restrito, mesmo assim foi possível reconhecer, compreender as ações coletivas realizadas por meio de recursos tecnológicos.

Os resultados dessa investigação sugerem a proposição da construção de OA de autoria coletiva como uma forma de resistência política e também como uma incorporação necessária às práticas pedagógico-dialógicas envolvendo pesquisa, colaboração, recriação e envolvimento dos estudantes com a produção do saber na e em rede. Para o desenvolvimento dos $O A$, foi necessário um movimento de interação e de troca de conhecimentos, já que não existe criação desconectada do mundo vivido e do olhar dos estudantes e professores. A interconexão no ciberespaço oportuniza formas de aprender interdependentes, contribuindo com as capacidades de aquisição de informação, de expressão e de deliberação dos sujeitos. Essa partilha do saber, por intermédio do ciberespaço e de comunidades educacionais, permite potencializar as competências humanas, que são capazes de se reinventar, promovendo momentos de criação contínua no mundo coletivo. Para Lévy (1998), a invenção de novos procedimentos em rede, como a construção de $\mathrm{OA}$, propostos pelos cursos de $\mathrm{EaD}$ investigados, permite $\mathrm{O}$ desenvolvimento das potências criativas e faz aflorar a formação da inteligência coletiva. Dentre os aspectos relevantes dessa pesquisa, podemos elencar que a construção de um OA não seria só um recurso didático-pedagógico, pois envolve ideologias e abertura para o potencial da imaginação criadora em novas formas de apreender o mundo, rompendo com ações objetivistas, estagnadas, competitivas e superficiais, de práticas pedagógicas técnico-operacionais, passivas e automatizadas.

As contradições encontradas para o desenvolvimento de OA de autoria coletiva vão desde o analfabetismo digital, os preconceitos contra a EaD entre intelectuais e professores com carreiras consolidadas, além de críticas às metodologias que separam a aprendizagem da construção do conhecimento e do ensino, mantendo lugares fixos e rígidos. O diálogo, a escuta, o reconhecimento das diferenças e a aceitação do outro levam a esferas moventes e aprendentes nos processos pedagógicos, que contribuem com os processos cognitivos e com 0 desenvolvimento coletivo. Tivemos presente nesse trabalho algumas experiências das protagonistas nessa proposição de construção de $O A$, num universo complexo e plural e em permanente mutação e avaliação, desvelando um grande potencial de sentido à educação, à realização de projetos solidários e com produção de conteúdo próprio no ciberespaço.

\section{Referências}

AYUB, Adriano de Oliveira Santos; CARVALHO, Daniel Siqueira; TEIXEIRA, Ítalo Hauer. Objetos de aprendizagem. 2006. 80 f. Monografia (Bacharelado em Desenho Industrial) - Universidade de Brasília, Brasília, 2006. Disponível em: <http://bdm.unb.br/handle/10483/138> Acesso em: 15 ago. 2018.

BRANSFORD, John; BROWN, Ann; COCKING, Rodney R. (Orgs.). Como as pessoas aprendem: cérebro, mente, experiência e escola. Trad. Carlos David Szkaj. São Paulo: Editora Senac, 2007.

CONTE, Elaine; HABOWSKI, Adilson Cristiano; RIOS, Miriam Benites. Ressonâncias das tecnologias digitais na educação. Revista Ibero-Americana de Estudos em Educação, Araraquara, v. 14, p. 31-45, 2019. Disponível em: <http://periodicos.fclar.unesp.br/iberoamericana/article/viewFile/11110/7869> Acesso em: 08 jan. 2019.

CONTE, Elaine; HABOWSKI, Adilson Cristiano. A autoridade do educador no cenário tecnológico: interlocuções freireanas. Revista Interinstitucional Artes de Educar. Rio de Janeiro, v. 4, n. 2, p. 406-425, 2018. DOI: $10.12957 /$ riae.2018.38035

FERREIRA, Hugo Monteiro. A literatura na sala de aula: uma alternativa de ensino transdisciplinar. 2007. 337 f. Tese (Doutorado em Educação) - Universidade Federal do Rio Grande do Norte, Natal, 2007.

FLÔRES, Maria Lucia Pozzatti. Metodologia para criar objetos de aprendizagem em matemática usando combinação de ferramentas de autoria. 2011. 210 f. Tese (Doutorado em Informática na Educação) - 
Universidade Federal do Rio Grande do Sul, Porto Alegre, 2011. Disponível em: $<$ www.lume.ufrgs.br/handle/10183/39669>. Acesso em: 10 set. 2018.

FREIRE, Paulo. Pedagogia do Oprimido. Rio de Janeiro: Paz e Terra, 1983.

FREIRE, Paulo. Pedagogia da autonomia: saberes necessários à prática educativa. 43. ed. São Paulo: Paz e Terra, 2011.

GADAMER, Hans-Georg. Verdade e Método I: traços fundamentais de uma hermenêutica filosófica. 3. ed. Trad. Flávio Paulo Meurer. Petrópolis, RJ: Vozes, 1999.

HABERMAS, Jürgen. Agir comunicativo e razão destranscendentalizada. Trad. Lucia Aragão. Rio de Janeiro: Tempo Brasileiro, 2002.

HABOWSKI, Adilson Cristiano; JACOBI, Daniel Felipe; CONTE, Elaine. Garimpando ideias para a reconstrução do círculo hermenêutico e do círculo de cultura. Revista Teias, Rio de Janeiro, v. 19, n. 53, abr./jun. 2018. DOI 10.12957/teias.2018.29719

LEMOS, André; LÉVY, Pierre. O futuro da internet: em direção a uma ciberdemocracia. São Paulo: Paulus, 2010.

LÉVY, Pierre. As tecnologias da inteligência: o futuro do pensamento da era da informática. Rio de Janeiro: Ed. 34, 1993.

LÉVY, Pierre. A inteligência coletiva. Por uma antropologia do ciberespaço. Trad. Luiz Paulo Rouanet. São Paulo: Edições Loyola, 1998.

MATURANA, Humberto R.; VARELA, Francisco J. A Ontologia da Realidade. Belo Horizonte: Ed. UFMG, 2002.

MOREIRA, Marco Antonio. Teorias de Aprendizagem. São Paulo: EPU, 2011.

NASCIMENTO, Anna Christina de Azevedo. Objetos de Aprendizagem: entre a promessa e a realidade. In: PRATA, Carmem Lúcia; NASCIMENTO, Anna Christina Aun de Azevedo Nascimento (Org.). Objetos de aprendizagem: uma proposta de recurso pedagógico. Brasília: MEC, SEED, 2007. p. 135-146. Disponível em: <http://rived.mec.gov.br/artigos/livro.pdf> Acesso em: 17 ago. 2018.

NUNES, Helena de Souza; RANGEL, Annamaria Píffero; SCHRAMM, Rodrigo. Primeiros Resultados e Considerações Finais. In: NUNES, Helena de Souza (Org.). EAD na formação de professores de música: fundamentos e prospecções. Tubarão: Copiart, 2012. p. 295-307.

PRATA, Carmem Lúcia; NASCIMENTO, Anna Christina de Azevedo Nascimento; PIETROCOLA, Maurício. Políticas para fomento de produção e uso de objetos de aprendizagem. In: PRATA, Carmem Lúcia; NASCIMENTO, Anna Christina Aun de Azevedo Nascimento (Org.). Objetos de aprendizagem: uma proposta de recurso pedagógico. Brasília: MEC, SEED, 2007. p. 107-121. Disponível em: <http://rived.mec.gov.br/artigos/livro.pdf> Acesso em: 18 ago. 2018.

SANCHO, Juana María; HERNÁNDEZ, Fernando. Tecnologias para transformar a educação. Porto Alegre: Artmed, 2006.

TAROUCO, Liane Margarida Rockenbach et al. (Org.). Objetos de Aprendizagem: Teoria e Prática. Porto Alegre: Evangraf, 2014. Disponível em: <http://www.lume.ufrgs.br/handle/10183/102993> Acesso em: 17 ago. 2018.

VYGOTSKY, Lev Semenovich. A formação social da mente: o desenvolvimento dos processos psicológicos superiores. São Paulo: Martins Fontes, 1998. 


\section{Maristela Vigolo Fontana}

Mestra em Educação (UNILASALLE), Técnico em assuntos educacionais na Secretaria de Educação a Distância (UFRGS), membro do Núcleo de Estudos sobre Tecnologias na Educação. E-mail: maristelavvigolo@yahoo.com.br

\section{Elaine Conte}

Doutora em Educação (UFRGS), Professora do Programa de Pós-Graduação em Educação da Universidade La Salle e líder do grupo NETE/UNILASALLE/CNPq, Canoas, Brasil. E-mail: elaine.conte@unilasalle.edu.br

\section{Adilson Cristiano Habowski}

Mestrando em Educação, membro do Núcleo de Estudos sobre Tecnologias na Educação - NETE/CNPq. Bolsista CAPES/PROSUC. E-mail: adilsonhabowski@hotmail.com 